\title{
EVALUASI KEBERHASILAN BAURAN PENYEWA MALL KUNINGAN CITY
}

\author{
Sandio Adhya Bayudi $\mathrm{M}^{1 \text { ) }}$, Priyendiswara Agustina Bela ${ }^{2)}$, Parino Rahardjo ${ }^{3)}$ \\ 1)Program Studi S1 PWK, Fakultas Teknik, Universitas Tarumanagara, sandiomarpaung05@gmail.com \\ 2)Program Studi S1 PWK, Fakultas Teknik, Universitas Tarumanagara, hedy.agustina@gmail.com \\ 3)Program Studi S1 PWK, Fakultas Teknik, Universitas Tarumanagara, parino19@gmail.com
}

Masuk: 24-08-2020, revisi: 28-09-2020, diterima untuk diterbitkan: 29-09-2020

\begin{abstract}
Abstrak
Penulisan ini bertujuan untuk mengetahui bauran penyewa yang tepat bagi pusat perbelanjaan Mall Kuningan City dalam upaya untuk meningkatkan jumlah arus pengunjung dan penyewa. Mall Kuningan City memiliki konsep Lifestyle \& Entertainment yang bertujuan untuk melengkapi akan kebutuhan dan hiburan bagi disekitar cakupan area Kecamatan Setiabudi, Jakarta Selatan. Dalam hal ini, maka dilakukan beberapa analisis yaitu analisis lokasi, analisis komparasi antara Mall Kuningan City dengan kompetitornya, dan analisis persepsi dan perspektif masyarakat, dengan bantuan beberapa alat analisa yang akan digunakan yaitu deskriptif, SWOT, comparison method, dan kuesioner. Dari hasil analisis yang diperoleh tersebut akan digunakan sebagai bahan pertimbangan untuk strategi pengelolaan yang baru bagi Mall Kuningan City dalam upaya meningkatkan jumlah arus pengunjung dan penyewa.
\end{abstract}

Kata kunci: bauran penyewa; pusat perbelanjaan; strategi pengelolaan; tingkat okupansi

\begin{abstract}
This study aims to determine the right tenant mix for the Kuningan City Mall shopping center in an effort to increase the number of visitors and tenants. Kuningan City Mall has a Lifestyle \& Entertainment concept that aims to complement the needs and entertainment for the surrounding area of the Setiabudi District, South Jakarta. In this case, several analyzes are conducted, namely location analysis, market analysis, comparative analysis of Mall Kuningan City with its competitors, and analysis of people's perspectives and perspectives, with the help of several analytical tools to be used namely descriptive, SWOT, comparison method, questionnaire. The analysis results obtained will be used as consideration for a new management strategy for Kuningan City Mall in an effort to increase the number of visitors and tenants.
\end{abstract}

Keywords: competitors; management strategy; occupancy rate; shopping center; tenant mix

\section{PENDAHULUAN}

Dinamika dan hiruk pikuk Kota Metropolitan Jakarta yang kian meningkat dan semakin padat penduduknya, membutuhkan ruang sentra yang mampu menyajikan segala macam kebutuhan masyarakat untuk mendukung kebutuhan kehidupan sehari - hari yang juga membantu menjaga roda ekonomi agar terus berjalan dengan stabil. Sehingga hal inilah yang menjadi salah satu pemicu pembangunan di Kota Jakarta terus meningkat guna untuk melengkapi sarana kebutuhan utama masyarakat di pusat kota khususnya Kota Jakarta. Salah satu pembangunan ruang sentra yang dapat mendukung kebutuhan hidup sehari - hari masyarakat tersebut adalah dengan dihadirkannya zona khusus untuk bangunan yang bersifat komersial yang biasa sering kita sebut dengan pusat perbelanjaan atau istilah lainnya yaitu shopping mall/shopping center. Tingginya tingkat konsumsi masyarakat khususnya di Kota Jakarta membuat para pengembang berlomba - lomba membangun pusat perbelanjaan atau shopping mall, sehingga mendorong para developer untuk bersaing dalam menggunakan strategi yang berbeda - beda untuk menarik jumlah pengunjung. Akan tetapi hal tersebut juga telah mengakibatkan beberapa 
dampak negatif, seperti contohnya kemacetan pada lalu lintas sehingga diberlakukan moratorium terhadap pembangunan mall untuk mengantisipasi hal tersebut. Dengan demikian pusat perbelanjaan yang ada di Jakarta dapat terkendali dan tentunya diharapkan dapat memenuhi kebutuhan masyarakat serta memajukan ekonomi perkotaan.

Artikel ini akan membahas permasalahan mengenai pengelolaan pusat perbelanjaan dengan objek utama yaitu Mall Kuningan City. Keberhasilan dari suatu pusat perbelanjaan dapat dipengaruhi oleh cara pengelola dalam mengelola pusat perbelanjaan/mall tersebut. Oleh karena itu, akan membahas mengenai pengelolaan terutama dalam tata letak pembauran penyewa Mall Kuningan City.

Mall Kuningan City berdiri dan mulai beroperasi dalam kurun waktu 3 tahun sejak 2011 hingga 2013, dimana Kuningan City sebagai mall yang paling tua diantara kedua shopping center tersebut yakni Lotte Shopping Avenue dan Kota Kasablanka, namun dalam jangka waktu yaitu kurang lebih 6 tahun hingga pada penyusunan tugas akhir ini Mall Kuningan City tetap saja memiliki tingkat okupansi yang paling rendah dan pengunjung yang lebih sedikit dibandingkan dengan kompetitornya yaitu Lotte Shopping Avenue dan Kota Kasablanka yang berada dalam cakupan radius 1,5 hingga 2 km dari Mall Kuningan City.

\section{Rumusan Permasalahan}

Permasalahan yang muncul berdasarkan studi awal di Kuningan City adalah tenant yang dimiliki mall Kuningan City ini tidak terisi penuh, hanya memiliki occupancy rate atau jumlah tenant dari kesuluruhan penyedian penempatan tenant yaitu sekitar $65 \%$ saja, karena sistem penyewaan yang tidak homogen padahal kelas penyewanya sama. Peneliti perlu mengetahui kondisi Mall Kuningan City saat ini, sehingga bisa mengetahui bauran penyewa Kuningan City dan perbelanjaan yang ada disekitarnya, dan permasalahan tersebut dapat dianalisa dan menghasilkan data yang bisa membantu menambah pengunjung dan penywa di Mall Kuningan City.

\section{Tujuan}

Tujuan dari penelitian ini adalah untuk mengetahui dan menganalisa kondisi Mall Kuningan City berdasarkan lokasi yang dapat menunjukkan potensi dan masalah, tenancy mix, preferensi dan persepsi pengunjung dan juga kompetitor Mall Kuningan City dan mal kompetitor. Adapaun tujuan penelitian ini mendapatkan usulan rencana bauran penyewa yang tepat sehingga dapat menarik pengunjung ke Mall Kuningan City.

\section{KAJIAN LITERATUR}

Menurut International Council of Shopping Centre (ICSC), definisi pusat perbelanjaan adalah sekelompok lokasi usaha ritel dan usaha komersial lainnya yang direncanakan, dikembangkan, dimiliki, dan dikelola sebagai suatu properti tunggal. Menurut Levy dan Weitz (2004) dan Neo (2005). pusat perbelanjaan juga dapat didefinisikan sesuai penyewa utama (anchor tenant), luas kotor area yang disewakan (gross leaseable area/GLA), dan wilayah bisnis. Keberhasilan atau kegagalan pusat perbelanjaan juga bergantung pada tenant mix. Tenant mix yang tepat dan lokasi toko dalam pusat perbelanjaan sangat berpengaruh pada keuntungan para penyewa. Tenant mix yang efektif akan menarik lalu lintas pelanggan ke pusat perbelanjaan. Berikut ini merupakan klasifikasi tenant mix dari ULI Shopping Center Handbook Series:

Tabel 1. Klasifikasi Tenancy Mix menurut ULI Shopping Center Handbook Series

\begin{tabular}{ll}
\hline \multicolumn{1}{c}{ Klasifikasi Penyewa } & \multicolumn{1}{c}{ Jenis Usaha } \\
\hline General Merchandiser & Department Store, Junior Department Store \\
\hline Food & $\begin{array}{l}\text { Supermarket, Specialty Food, Bakery, Candy and Nuts, Dairy } \\
\text { Product, Health Food }\end{array}$ \\
\hline
\end{tabular}




\begin{tabular}{|c|c|}
\hline Klasifikasi Penyewa & Jenis Usaha \\
\hline Food Service & $\begin{array}{l}\text { Restaurant, Cafetaria, Fast Food, Doughnut Shop, Ice Cream Parlor, } \\
\text { Prezel Shop, Cookie Shop }\end{array}$ \\
\hline Clothing & $\begin{array}{l}\text { Ladies Specialty, Bridal Shop, Childrens Wear, Mens Wear, Family } \\
\text { Wear, Unisex / Jeans Shop, Uniform Shop }\end{array}$ \\
\hline Shoes & $\begin{array}{l}\text { Family Shoes, Ladies Shoes, Men`s and boy`s shoes, Childern`s shoes, } \\
\text { Athletic Footwear }\end{array}$ \\
\hline Home Furnishing & $\begin{array}{l}\text { Furniture, Lamps, Floor Coverings, Curtains, China and Glassware, } \\
\text { Bath Shop, Contemporary Home Accessories }\end{array}$ \\
\hline $\begin{array}{l}\text { Home Appliances / } \\
\text { Music }\end{array}$ & $\begin{array}{l}\text { Radio, Video, Stereo, Sewing Machines, Records and Tapes, Musical } \\
\text { Instrument, Computer (Retail) }\end{array}$ \\
\hline Building Materials & Paint and Wallpaper, Hardware, Home Improvements \\
\hline Automotive Supplies & Automotive \\
\hline $\begin{array}{l}\text { Hobby / Special } \\
\text { Interest }\end{array}$ & $\begin{array}{l}\text { Sporting Goods, Hobby, Art Gallery, Cameras, Toys, Bike Shop, Art } \\
\text { and Craft, Game Store }\end{array}$ \\
\hline $\begin{array}{l}\text { Gifts / Specialty } \\
\text { Interest }\end{array}$ & $\begin{array}{l}\text { Imports, Luggage and Leather, Card and Gift, Candle, Books and } \\
\text { Stationary, Decorative Accessories }\end{array}$ \\
\hline Jewelry and Cosmetics & Costume Jewelry, Jewelry, Cosmetics \\
\hline Liquor & Liquor and Wine, \\
\hline Drugs & Super Drugs, Drugs \\
\hline Other Retail & $\begin{array}{l}\text { Fabric Shop, Tobacco, Pet Shop, Flowers, Plant Store, Telephone } \\
\text { Store, Optical }\end{array}$ \\
\hline Personal Service & $\begin{array}{l}\text { Beauty, Barber, Shoe Repair, Laundry, Health and Spa / Salon, } \\
\text { Photographer, Formal Wear Rental, Travel Agent, Key Shop, Film } \\
\text { Processing, Photocopy }\end{array}$ \\
\hline $\begin{array}{l}\text { Recreation/ } \\
\text { Community }\end{array}$ & $\begin{array}{l}\text { Post Office, Music Studio, Bowling Alley, Cinemas, Ice Roller Skating, } \\
\text { Community Hall, Arcade, Amusement, Day care and Nursery }\end{array}$ \\
\hline Financial & $\begin{array}{l}\text { Banks, Saving and Loan, Finance Company, Brokerage, Insurance, } \\
\text { Automatic Teller Machine }\end{array}$ \\
\hline Office & Medical and Dental, Legal, Employment Agency \\
\hline Other Retail & Vacant Space, Warehouse \\
\hline
\end{tabular}

Sumber: ULI Shopping Center Handbook Series, 1999

\section{METODE}

Metode yang akan dilakukan pada penelitian ini dalam rangka memperoleh data dalam penelitian ini adalah metode pengumpulan primer dan sekunder. Data Primer yaitu pengumpulan data primer merupakan pengumpulan data yang diperoleh secara langsung oleh peneliti dari sumber pertama melalui: (1) Survey/observasi: Survey yang dimaksud adalah dengan melakukan pengamatan langsung di lapangan sehingga dapat memperoleh kondisi aktual mengenai visibilitas, aksesibilitas, luasan, fasilitas, tenant mix, anchor tenant, (2) Kuesioner: Penyebaran kuesioner dilakukan kepada pengunjung dan penyewa di Mall Kuningan City, (3) Dokumentasi: Dokumentasi diperoleh pada saat melakukan observasi, dokumentasi yang diperoleh yaitu berupa foro dari pusat perbelanjaan yang diteliti, foto yang terkait dengan materi penelitian. Sedangkan Data Sekunder merupakan pengumpulan data yang diperoleh secara tidak langsung. Data yang digunakan pada penelitian ini berupa informasi - informasi yang terkait dengan objek penelitian yang diteliti seperti data peta dan lokasi objek, data kependudukan dan data - data umum pusat perbelanjaan seperti tenant mix, denah, zonasi.

Ruang lingkup lokasi studi ini adalah Mall Kuningan City yang merupakan pusat perbelanjaan yang memiliki lokasi yang strategis berada pada kawasan segitigas mas, tepat berada di JI Prof. Dr. Satrio yang dilalui oleh setiap aktivitas ekonomi di Jakarta. 


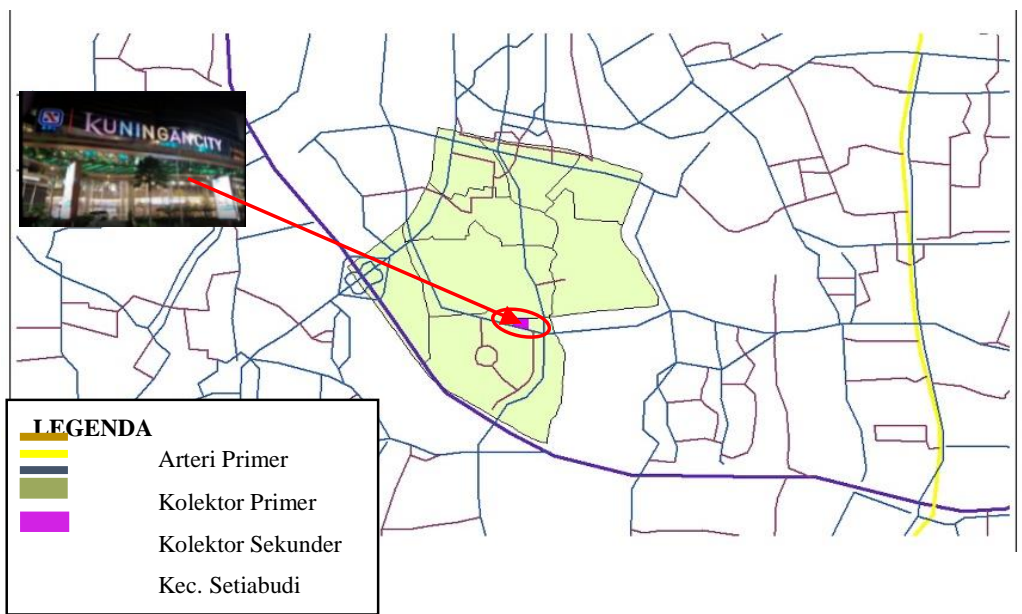

Gambar 1. Peta Aksesibilitas Mall Kuningan City

Sumber: Olahan Pribadi, 2019

Selain metode pengumpulan data, metode analisa juga diperlukan untuk dapat menghasilkan hasil penelitian yang lebih terstruktur yang dapat menjawab tujuan dari penelitian ini yang disesuaikan dengan cara untuk mengolah data yang telah dikumpulkan, terdapat beberapa metode analisis yang akan dilakukan yaitu: (1) Metode Deskriptif: Melalui metode ini dapat diperoleh gambaran tentang suatu hal dengan menggunakan data - data yang telah dikumpulkan dan kemudian menyajikannya dalam bentuk tabel maupun grafik. Tujuannya adalah data - data tersebut dapat disajikan dalam bentuk yang lebih ringkas sehingga mudah dipahami, (2) Pengumpulan Sampel: Metode ini digunakan untuk menentukan besarnya jumlah sampel kuesioner dari responden yang merupakan pengunjung dan penyewa dari mall Kuningan City dalam rangka ingin mengetahui kondisi mall Kuningan City, (3) SWOT: adalah metode perencanaan strategis yang digunakan untuk mengevaluasi kekuatan, kelemahan, peluang, dan ancaman dalam suatu objek, (4) Comparison Method: adalah metode yang digunakan untuk membandingkan suatu atau beberapa nilai sehingga dapat menghasilkan perbandingan antar nilai tersebut.

\section{DISKUSI DAN HASIL}

Tabel 2 di bawah ini adalah hasil analisa SWOT objek studi Mall Kuningan City menurut dari kondisi eksisting.

Tabel 2. SWOT Mall Kuningan City

\begin{tabular}{|c|c|c|c|}
\hline \multirow[t]{6}{*}{ Internal } & \multicolumn{2}{|r|}{ Strength } & Weakness \\
\hline & \multirow{2}{*}{\multicolumn{2}{|c|}{$\begin{array}{l}\text { 1) Lokasi Mall Kuningan City yang sangat } \\
\text { strategis yaitu berlokasi di kawasan mega } \\
\text { kuningan jakarta atau segitiga mas jakarta } \\
\text { dan di kelas jalan arteri sekunder Jl. Prof. Dr. } \\
\text { Satrio }\end{array}$}} & $\begin{array}{l}\text { 1) Anchor tenant/penyewa berada } \\
\text { ditempat yang tidak sesuai }\end{array}$ \\
\hline & & & 2) Tingkat okupansi rendah \\
\hline & 2) & $\begin{array}{l}\text { Kuningan City berada dilingkungan komersial } \\
\text { dimana terdapat apartemen, perkantoran, } \\
\text { dan juga beberapa instansi pemerintahan } \\
\text { lainnya. }\end{array}$ & $\begin{array}{l}\text { 3) Façade atau tampak luar gedung } \\
\text { yang sudah kurang menarik dan } \\
\text { tertutupi oleh flyover. }\end{array}$ \\
\hline & 3) & $\begin{array}{l}\text { Konsep Lifestyle, Kuningan Clty masih dapat } \\
\text { hidup karena kebutuhan orang disekitarnya }\end{array}$ & 4) Fasilitas yang kurang \\
\hline & \multicolumn{2}{|r|}{ Opportunity } & Threat \\
\hline Eksternal & 1) & $\begin{array}{l}\text { Terdapat rencana titik MRT yang dapat } \\
\text { menjadi nilai lebih lagi dalam transportasi } \\
\text { karna aksesibilitasnya bertambah }\end{array}$ & $\begin{array}{l}\text { 1) Persaingan yang ketat dengan } \\
\text { beberapa Mall yang menjadi } \\
\text { kompetitor disekitar Kuningan City }\end{array}$ \\
\hline
\end{tabular}

Sumber: Olahan Pribadi, 2020 


\section{Perbandingan Objek Studi dengan Kompetitor Sekitar}

Analisis ini akan dilakukan dengan metode komparasi antara data eksisting Mall Kuningan City dan kedua kompetitornya yaitu Lotte Sopping Avenue dan Kota Kasablanka. Data yang aka menjadi perbandingan melingkupi profil mall, tenancy mix dalam angka jumlah dan klasifikasinya masing - masing.

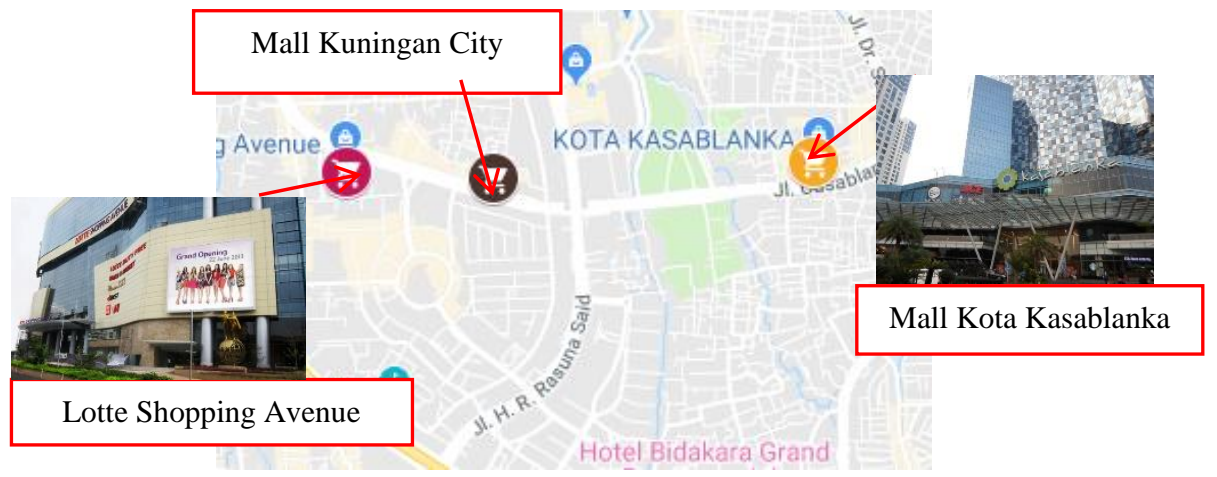

Gambar 2. Peta Kompetitor Mall Kuningan City

Sumber: Survey sekunder, 2019

Berdasarkan catchment area yang dapat dilihat dari peta diatas terdapat kompetitor yang masuk dalam radius 2 km, yaitu Mall Kota Kasablanka dan Lotte Shopping Avenue. Maka dari itu akan dipilih mall yang memilki karakteristik yang sama dengan Mall Kuningan City. Berikut tabel 4 yang berisi penjelasan profil kompetitor.

Tabel 3. Profil Kompetitor Mall Kuningan City

\begin{tabular}{|c|c|c|c|c|}
\hline No & Faktor & $\begin{array}{c}\text { Mall Kota } \\
\text { Kasablanka }\end{array}$ & $\begin{array}{l}\text { Lotte Shopping } \\
\text { Avenue }\end{array}$ & $\begin{array}{c}\text { Mall Kuningan } \\
\text { City }\end{array}$ \\
\hline 1 & Luas & $110.000 \mathrm{~m} 2$ & $77.000 \mathrm{~m} 2$ & $85.000 \mathrm{~m} 2$ \\
\hline 2 & Leaseable area & $78.000 \mathrm{~m} 2$ & $47.000 \mathrm{~m} 2$ & $56.000 \mathrm{~m} 2$ \\
\hline 3 & $\begin{array}{l}\text { Harga Sewa Rata2 } \\
\text { /lantai/bulan }\end{array}$ & $825.000 \mathrm{~m} 2$ & $575.000 \mathrm{~m} 2$ & $550.000 \mathrm{~m} 2$ \\
\hline 4 & Service Charge & $\begin{array}{c}173.500 \mathrm{~m} 2 \\
\text { /bulan }\end{array}$ & $\begin{array}{c}145.000 \mathrm{~m} 2 \\
\text { /bulan }\end{array}$ & $\begin{array}{l}108.000 \mathrm{~m} 2 \\
\text { /bulan }\end{array}$ \\
\hline 5 & Occupancy Rate & $95 \%$ & $90 \%$ & $65 \%$ \\
\hline 6 & Jumlah Tenant & 409 & 134 & 181 \\
\hline 7 & Jumlah Anchor Tenant & 5 & 4 & 3 \\
\hline 8 & Tahun Beroperasi & 2012 & 2013 & 2011 \\
\hline 9 & Umur Bangunan & 8 Tahun & 7 Tahun & 9 Tahun \\
\hline 10 & Developer & Pakuwon Group & Ciputra & $\begin{array}{c}\text { Agung } \\
\text { Podomoro }\end{array}$ \\
\hline 11 & Jumlah Lantai & 6 & 7 & 6 \\
\hline 12 & Jumlah Entrance & 3 & 3 & 3 \\
\hline 13 & Parkir Basement & Ada & Ada & Ada \\
\hline 14 & Parkir Gedung & Tidak Ada & Ada & Ada \\
\hline 15 & Parkir Outdoor & $\begin{array}{l}\text { Ada (Khusus } \\
\text { Motor) }\end{array}$ & $\begin{array}{l}\text { Ada (Khusus } \\
\text { Motor) }\end{array}$ & Tidak Ada \\
\hline 16 & Konsep & $\begin{array}{l}\text { Modern Concept } \\
\text { Shopping }\end{array}$ & $\begin{array}{c}\text { Love Your } \\
\text { Passion, Love } \\
\text { Your Life }\end{array}$ & $\begin{array}{l}\text { Lifestyle and } \\
\text { Entertainment }\end{array}$ \\
\hline
\end{tabular}




\begin{tabular}{clccc}
\hline No & Faktor & $\begin{array}{c}\text { Mall Kota } \\
\text { Kasablanka }\end{array}$ & $\begin{array}{c}\text { Lotte Shopping } \\
\text { Avenue }\end{array}$ & $\begin{array}{c}\text { Mall Kuningan } \\
\text { City }\end{array}$ \\
\hline 17 & Target Market & Menengah Atas & Menengah Atas & $\begin{array}{c}\text { Menengah } \\
\text { Atas }\end{array}$ \\
\hline 18 & Event Promotion & Setiap Hari & Setiap Minggu & Tidak Menentu \\
\hline 19 & $\begin{array}{l}\text { Akses Angkutan } \\
\text { umum }\end{array}$ & Ada & Ada & Ada \\
\hline
\end{tabular}

Sumber: Olahan penelitian 2019

Berdasarkan tabel diatas, dapat kita lihat bahwa ketiga mall ini berada pada kelas yang sama, dan konsep yang sama yaitu mix use (kawasan campuran) dimana ketiga mall mempunyai fungsi lebih dari sekedar pusat perbelanjaan yaitu adanya perkantoran maupun bangunan residensial seperti apartemen. Maka Mall Kota Kasablanka dan Lotte Shopping Avenue ditentukan sebagai kompetitor dari Mall Kuningan City. Dapat dilihat juga dari tabel diatas perbandingan jumlah tenant antara ketiga mall cukup besar yang juga dipengaruhi oleh luasan mall, dimana (1) Kota Kasblanka mempunyai penyewa terbanyak dan occupancy rate tertinggi yaitu 409 tenant dengan okupansi 95\%, (2) diikuti oleh Lotte Sopping Avenue sebanyak 181 dengan okupansi $90 \%$, (3) dan objek studi Kuningan City diperingkat terakhir dibandingkan kompetitornya dengan 134 tenant dan okupansi $65 \%$.

\section{Tenancy Mix}

Tenancy mix atau bauran penyewa merupakan strategi pencampuran penyewa ruang dari berbagai jenis barang. Penjabaran mengenai klasifikasi bauran penyewa menurut ULI, Shopping Center Development Handbook pada pusat perbelanjaan mal Kuningan City, yang kemudian diikuti dengan komparasi tenant terhadap kompetitor.

\section{Anchor Tenants}

Anchor Tenant (ULI, Shopping Center Development Handbook) yaitu campuran Sebuah pusat perbelanjaan yang tidak dapat ditentukan oleh rumus: setiap komunitas dan setiap pusat perbelanjaan berbeda. Berikut pada tabel diatas ini beberapa anchor tenant yang ada pada Kuningan City dan juga 2 kompetitor lainnya.

Tabel 4. Anchor Tenants masing - masing Pusat Perbelanjaan

\begin{tabular}{|c|c|c|c|c|}
\hline No. & Mall & $\begin{array}{c}\text { Jumlah Anchor } \\
\text { Tenant }\end{array}$ & Anchor Tenant & Klasfikasi Jenis Tenant \\
\hline \multirow[t]{3}{*}{1} & \multirow[t]{3}{*}{ Kuningan City } & \multirow[t]{3}{*}{3} & Ace Hardware & Building Materials/Garden \\
\hline & & & Cinema XXI & Recreation/Community \\
\hline & & & Lotte Mart & Food \\
\hline \multirow[t]{5}{*}{2} & \multirow{5}{*}{$\begin{array}{c}\text { Kota } \\
\text { Kasablanka }\end{array}$} & \multirow[t]{5}{*}{5} & Ace Hardware & Building Materials/Garden \\
\hline & & & Carrefour & Food \\
\hline & & & Cinema XXI & Recreation/Community \\
\hline & & & Informa & Home Furnishings \\
\hline & & & SOGO & General Merchandise \\
\hline \multirow[t]{4}{*}{3} & \multirow{4}{*}{$\begin{array}{l}\text { Lotte Shopping } \\
\text { Avenue }\end{array}$} & \multirow[t]{4}{*}{4} & Ace Hardware & Building Materials/Garden \\
\hline & & & Cinema XXI & Recreation/Community \\
\hline & & & Lotte Shopping Center & General Merchandise \\
\hline & & & Ranch Market & Food \\
\hline
\end{tabular}

Sumber: Olahan penilitian, 2020 
Dapat Dilihat dari pada tabel yang ada diatas, dimana masing - masing pusat perbelanjaan memiliki setidaknya satu anchor tenant atau lebih yang umumnya terdiri dari anchor tenant jenis General Merchandise, Food atau Recreation/Community, namun hal ini tidak menjamin bahwa semua pusat perbelanjaan sama. Berdasarkan tabel tersebut juga dapat ditarik kesimpulan bahwa jumlah dan jenis anchor tenant dapat mempengaruhi mall, dimana Kota Kasablanka mepunyai jumlah anchor tenant terbanyak dan juga mempunyai tenant dan tingkat okupansi tertinggi dibandingkan Kuningan City dan Lotte Shopping Avenue.

\section{Klasifikasi Tenant}

Berikut klasifikasi tenant atau bauran penyewa menurut ULI, Shopping Center Development Handbook antara Kuningan City dan kedua kompetitornya yaitu Kota Kasablanka dan Lotte Shopping Avenue.

Tabel 5. Klasifikasi Jenis Bauran Penyewa Masing - Masing Mall

\begin{tabular}{|c|c|c|c|c|c|c|c|}
\hline \multirow[t]{2}{*}{ No. } & \multirow[t]{2}{*}{ Jenis Penyewa } & \multicolumn{2}{|c|}{ Kuningan City } & \multicolumn{2}{|c|}{ Kota Kasablanka } & \multicolumn{2}{|c|}{$\begin{array}{l}\text { Lotte Shopping } \\
\text { Avenue }\end{array}$} \\
\hline & & Jum. & Persentase & Jum. & Persentase & Jum. & Persentase \\
\hline 1 & Automotive Supplies & - & - & - & - & - & - \\
\hline 2 & $\begin{array}{c}\text { Building } \\
\text { Materials/Garden }\end{array}$ & 1 & $1 \%$ & 1 & $0 \%$ & 1 & $1 \%$ \\
\hline 3 & Clothing & 18 & $14 \%$ & $* 73$ & $18 \%$ & 20 & $11 \%$ \\
\hline 4 & Drugs & 3 & $2 \%$ & $* 4$ & $1 \%$ & $* 4$ & $2 \%$ \\
\hline 5 & Financial & 4 & $3 \%$ & $* 10$ & $2 \%$ & 5 & $3 \%$ \\
\hline 6 & Food & 1 & $1 \%$ & 1 & $0 \%$ & 1 & $1 \%$ \\
\hline 7 & Food Service & 58 & $44 \%$ & $* 143$ & $35 \%$ & 66 & $36 \%$ \\
\hline 8 & General Merchandiser & 1 & $1 \%$ & - & - & $* 7$ & $4 \%$ \\
\hline 9 & Gifts/Specialty & 3 & $2 \%$ & 3 & $1 \%$ & 3 & $2 \%$ \\
\hline 10 & Hobby/Special Interest & 7 & $5 \%$ & $* 51$ & $12 \%$ & 13 & $7 \%$ \\
\hline 11 & $\begin{array}{c}\text { Home Appliances / } \\
\text { Music }\end{array}$ & 1 & $1 \%$ & $* 6$ & $1 \%$ & 2 & $1 \%$ \\
\hline 12 & Home Furnishing & - & - & $* 6$ & $1 \%$ & 5 & $3 \%$ \\
\hline 13 & Jewelry and Cosmetics & 1 & $1 \%$ & $* 23$ & $6 \%$ & 11 & $6 \%$ \\
\hline 14 & Liquor & $* 2$ & $2 \%$ & 1 & $0 \%$ & - & - \\
\hline 15 & Office & $* 5$ & $4 \%$ & 2 & $0 \%$ & 4 & $2 \%$ \\
\hline 16 & Other Retail & 3 & $2 \%$ & $* 8$ & $2 \%$ & 3 & $2 \%$ \\
\hline 17 & Personal Service & 16 & $12 \%$ & $* 36$ & $9 \%$ & 19 & $10 \%$ \\
\hline 18 & $\begin{array}{l}\text { Recreation/ } \\
\text { Community }\end{array}$ & 5 & $4 \%$ & 5 & $1 \%$ & $* 8$ & $4 \%$ \\
\hline 19 & Shoes & 4 & $3 \%$ & $* 36$ & $9 \%$ & 9 & $5 \%$ \\
\hline
\end{tabular}

Dari tabel data komparasi angka dan presentase tenant antara Kuningan City dan kedua kompetitornya diatas, kita bisa menarik beberapa kesimpulan yaitu simana Kota Kasablanka mempunyai jumlah tenant terbanyak dibandingkan kedua mall, terutama dalam kategori Clothing, Financial, Drugs, Food Service, Hobby/Special Interest, Home Appliances, Home Furnishing, Jewelry \& Cosmetics, Other Retail, Personal Service dan Shoes. Hal ini juga didukung karena mall Kota Kasablanka mempunyai area sewa yang paling luas dibandingkan keduanya. 
Lotte Shopping Avenue mempunyai jumlah tenant yang sama dengan Kota Kasablanka yaitu 4 tenant kategori Drugs, sedangkan Kuningan City memiliki 3 tenant. Kategori unggul lainnya yaitu General Merchandise yaitu Lotte Shopping Experience disetiap lantai dimana tenantnya terdiri dari ratusan varian jenis tenant yang tergabung didalamnya seperti Cosmetics, Accessories, Bags, Shoes, Fashion, Home Furnishings hingga Baby Products disetiap lantainya. Recreation/Community juga paling banyak dimiliki oleh Lotte Shopping Avenue yaitu 8 tenant yang sifatnya ramah untuk kanak - kanak. Kuningan City mempunyai kategori tenant Liqour dan Office yang jumlahnya lebih banyak dari kempetitornya bahkan Lotte Shopping Avenue tidak memiliki tenant dengan kategori Liqour.

\section{Tenancy Mix}

Lantai LG (lower ground)

\section{PRESENTASE KLASIFIKASI TENANT LOWER GROUND KUNINGAN CITY}

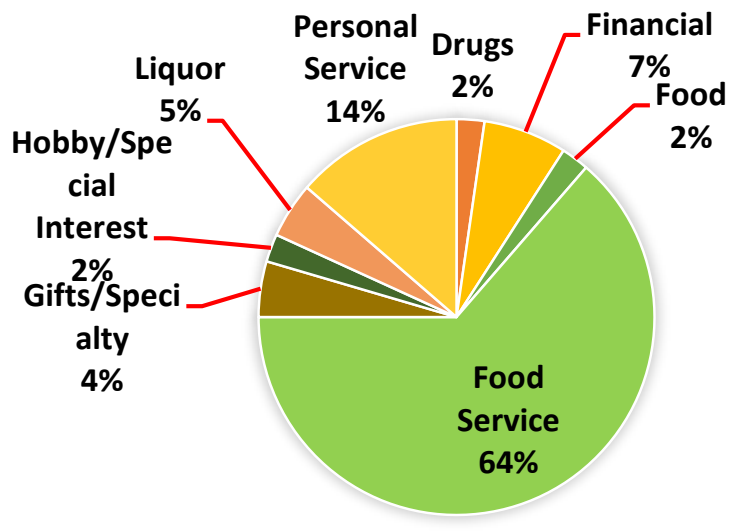

Gambar 3. Tenant Mix Lower Ground Sumber: Hasil penilitian 2019

Berdasarkan gambar 3 di atas terdapat anchor tenant berupa supermarket dan specialty tenant di lantai LG. Specialty tenant yang mendominasi adalah specialty tenant jenis food \& beverages, diantaranya Chatime, Baskin Robins, Shihlin dan 7th Corner Coffee. Kemudian specialty tenant jenis restaurant sebesar $64 \%$ diantaranya Solaria, Bale Nyoenya dan Kafe Betawi. Adanya bauran penyewa specialty food \& beverage dan anchor tenant Lotte Mart di lantai Low Ground menjadi salah satu penyebab minatnya pengunjung datang ke lantai ini.

\section{Lantai GF (Ground Floor)}

Dapat dilihat pada gambar 4, tenant yang mendominasi adalah Food \& Beverages $84 \%$ yang menjadi pusat kegiatan utama pusat perbelanjaan dimana pada saat rush our pada jam makan siang atau makan malam pengunjung dapat memenuhi penyewa yang ada di lantai GF yang terutama Tempat Makan dan Minum yang kemudian diikuti oleh, Clothing atau Fashion \& Accessories 9\%, dan Personal Service 5\%. 


\section{PRESENTASE KLASIFIKASI TENANT GROUND FLOOR KUNINGAN CITY}

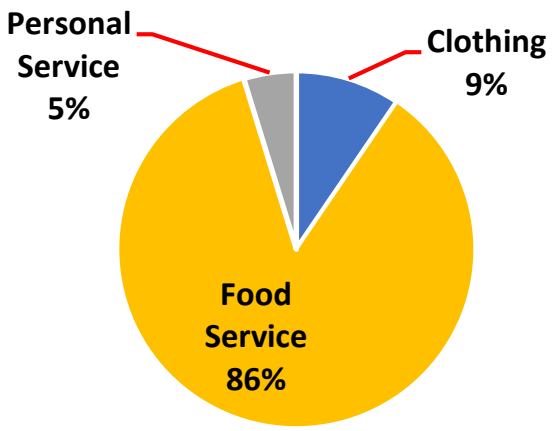

Gambar 4. Tenant Mix Ground Floor Sumber: Hasil penilitian 2019

Lantai UG (Upper Ground)

Berdasarkan Gambar 5 tenant yang mendominasi masih jenis tenant Clothing atau Fashion \& Accessories sebesar 44\%, tenant Food Service sebesar 13\%, dan Other Retail seperti Optik Seiss, Optik Melawai 13\%. Terdapat tenant General Merchandise Miniso, dan Specialty tenant di lantai UG diantaranya, Beverly Hills Polo Club, Timberland, Mango, dan Mozzo. Kemudian untuk tenant ritel lainnya terdapat Optik Seiss, Optik Melawai, Paxel, AXA Experience Zone dan Samsonite.

\section{PRESENTASE KLASIFIKASI TENANT UPPER GROUND KUNINGAN CITY}

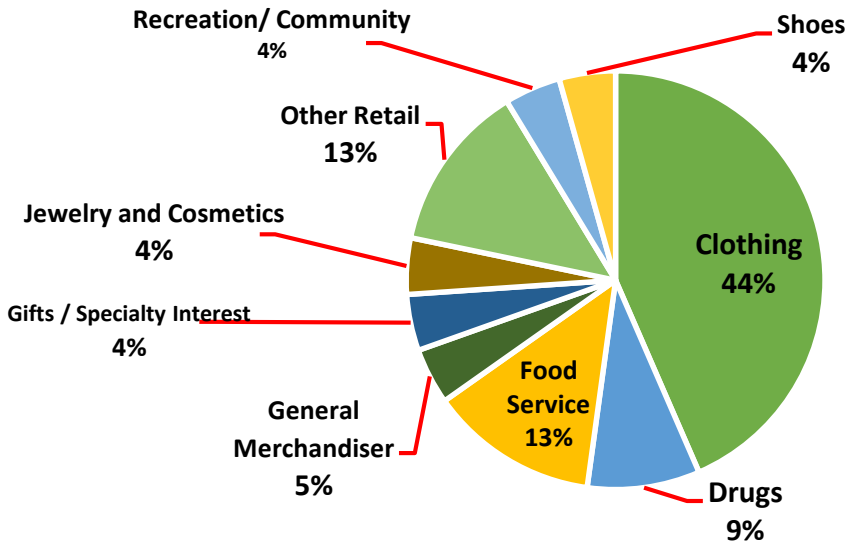

Gambar 5. Tenancy Mix UG

Sumber: Hasil penilitian 2019

\section{Lantai 1}

Pada lantai 1 terdapat 7 klasifikasi tenant diantaranya terdapat Food Service Ichiban Sushi, Sate Khas Senayan, Ta Wan, dan Gula Merah sebesar $18 \%$ yang mempunyai presentase sama dengan penyewa jenis Clothing yang diantaranya Red Tag, Antony Morata, Gino Mariani, dan Andre Valentino. Office diantaranya VFS Global, AIC Medical Clinic, Smec Eye Care, dan My'n Your Dentist sebesar $17 \%$ yang juga sama dengan penyewa jenis Hobby/Special Interest seperti Red Tag, Golf Depot, Kidz Station dan Sport Statio. 


\section{PRESENTASE KLASIFIKASI TENANT FIRST FLOOR (1ST) KUNINGAN CITY}

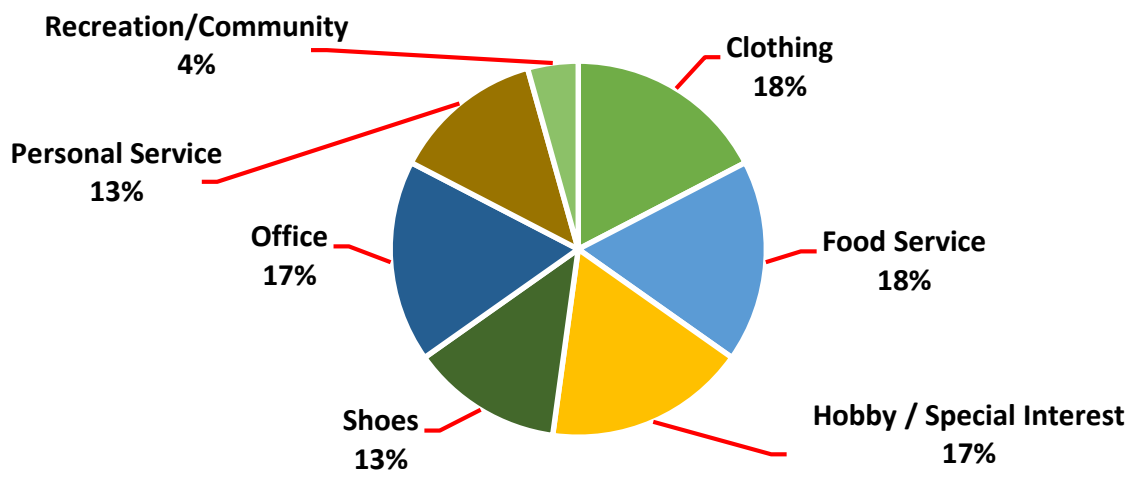

Gambar 6. Tenancy Mix Lantai 1

Sumber: Hasil penilitian 2019

\section{Lantai 2}

Pada lantai 2 terdapat 11 tenant dan terdapat 7 jenis tenant yang didominasi oleh Personal Servcice 46\% Diantaranya Satguru Travel \& Tours, Jatomi Fitness, Dandelion Independent Academy, GBI WOW, Mice Center, dan Shining Star. Lantai 2 juga terdapat 1 anchor tenant jenis Building Materials yaitu Ace Hardware.

\section{PRESENTASE KLASIFIKASI TENANT SECOND FLOOR (2ND) KUNINGAN CITY}

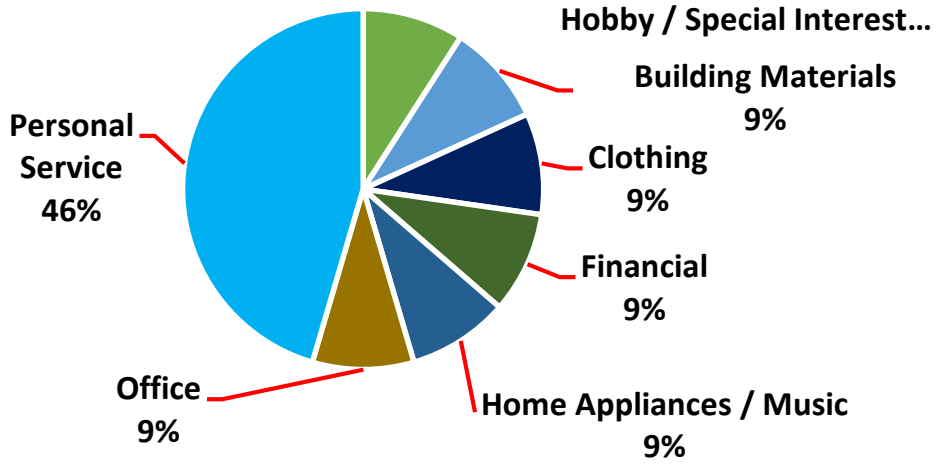

Gambar 7. Tenancy Mix Lantai 2

Sumber: Hasil penilitian 2019

\section{Lantai 3}

Pada lantai ini di dominasi oleh tenant dengan jenis Food Services $42 \%$ seperti Eatery dan restaurant tenant lainnya dan Recreation/Entertainment 25\% di mana terdapat 1 anchor tenant yaitu Cinema XXI. Lantai 3 di harapkan dapat menarik pengunjung karena memiliki 1 tenant anchor, lantai 3 merupakan salah satu magnet terjadinya arus pengunjung saling berpadu dengan tenant - tenant yang ada pada lantai basement atau lower ground floor dan ground floor. 


\section{PRESENTASE KLASIFIKASI TENANT THIRD FLOOR (3RD) KUNINGAN CITY}

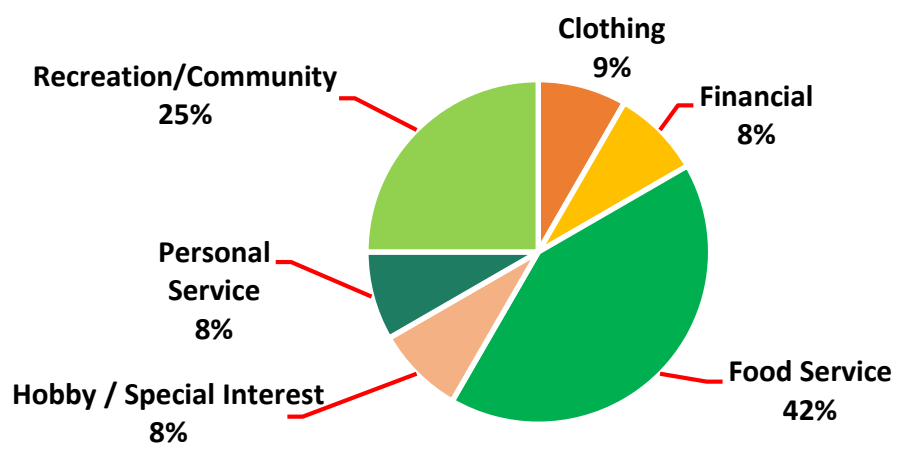

Gambar 8. Tenancy Mix Lantai 3

Sumber: Hasil penilitian 2019

\section{Persepsi \& Preferensi Pengunjung}

Pada tahap selanjutnya akan dilakukan proses pengolahan data yang sesuai dengan kebutuhan analisis yang ingin dihasilkan dari 100 responden yang mengisi form angket/kuesioner yang telah disebarkan. Berikut hasil dari penyebaran kuesioner yang berkaitan dengan persepsi dan preferensi pengunjung mengenai pusat perbelanjaan Kuningan City.

\section{Karakteristik Pengunjung}

Karakteristik umum pengunjung Mall Kuningan City dapat ditentukan dari jenis kelamin, usia, pekerjaan, domisili dan pendidikan dari 100 responden pengunjung tersebut.

Tabel 6. Karakteristik Pengunjung Mall Kuningan City

\begin{tabular}{|c|c|c|}
\hline \multicolumn{2}{|c|}{ Karakteristik Pengunjung } & Dominan \\
\hline 1) & Jenis kelamin & didominasi oleh perempuan yaitu sebanyak 53\%, \\
\hline 2) & Usia & $\begin{array}{l}\text { didominasi pada kategori dengan umur } 25 \text { tahun - } 35 \text { tahun } \\
\text { sebanyak 43\%, }\end{array}$ \\
\hline 3) & Pekerjaan & $\begin{array}{l}\text { didominasi oleh pengunjung dengan profesi sebagai Pegawai } \\
\text { sebanyak } 44 \% \text {, }\end{array}$ \\
\hline 4) & Domisili & $\begin{array}{l}\text { didominasi oleh penngunjung yang tinggal di daerah Jakarta } \\
\text { Selatan sebanyak } 39 \%\end{array}$ \\
\hline 5) & Pendidikan & $\begin{array}{l}\text { didominasi oleh pengunjung dengan pendidikan D3 yaitu } 34 \% \text {, } \\
\text { yang mempunyai perbedaan tipis dengan pendidikan S1 yaitu } \\
30 \% \text {. }\end{array}$ \\
\hline & Pendapatan & $\begin{array}{l}\text { didominasi oleh } 35 \% \text { pengunjung yang memiliki pendapatan } \\
\text { sekitar Rp } 2.500 .000 \text { hingga Rp } 5.000 .000 \text { perbulannya . }\end{array}$ \\
\hline
\end{tabular}

Sumber: Hasil olahan angket, 2020

Terdapat juga grafik dengan jenis radar yang dapat membantu kita untuk bisa melihat dominasi dari karakteristik pengunjung dengan ke enam variabel yaitu Jenis Kelamin, Usia, Pekerjaan, Domisili, Pendidikan, dan Pendapatan dari gambar 8 dibawah ini. 


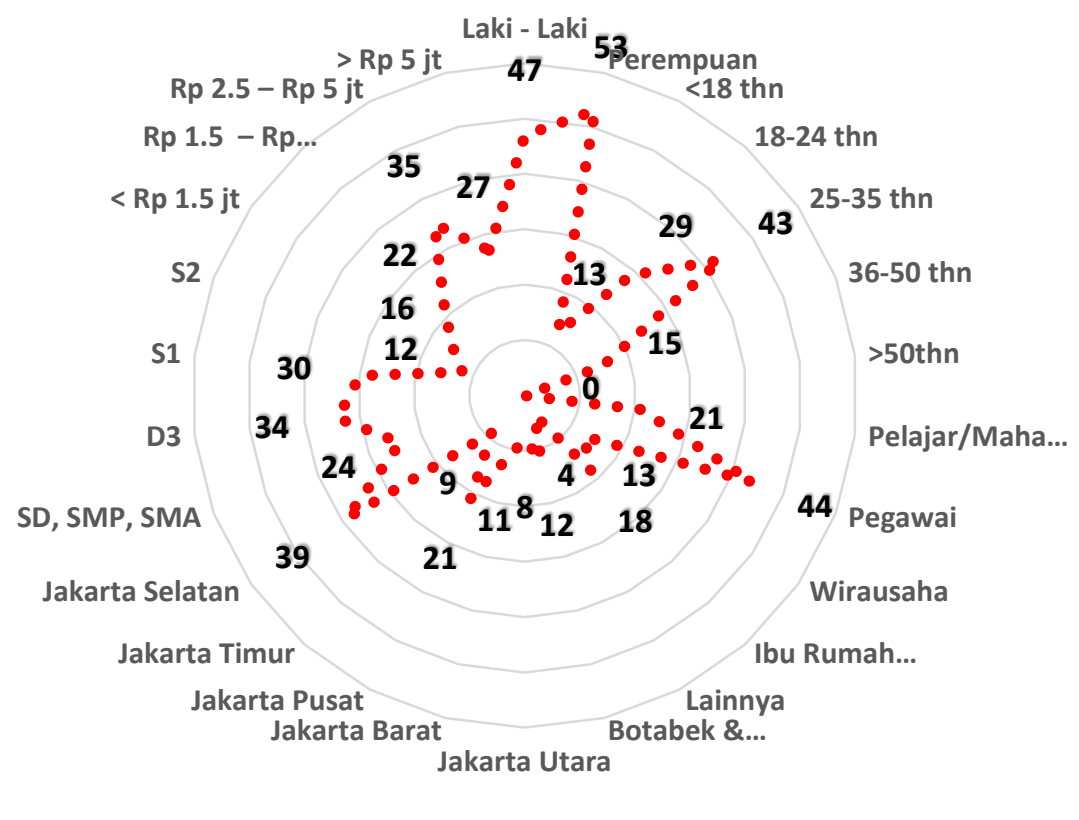

Gambar 9. Karakteristik Umum Pengunjung Mall Kuningan City Sumber: Hasil olahan data angket, 2020

Pengunjung yang mengunjungi Mall Kuningan City mempunyai tujuan utama yang berbeda beda dan bervariasi antara pengunjung satu dengan lainnya, untuk berkunjung ke pusat perbelanjaan juga membutuhkan transportasi dan juga adanya cost atau biaya yang harus dikeluarkan, berikut ini beberapa variabel pertanyaan umum yang ditujukan kepada 100 responden yang berkunjung ke Mall Kuningan City.

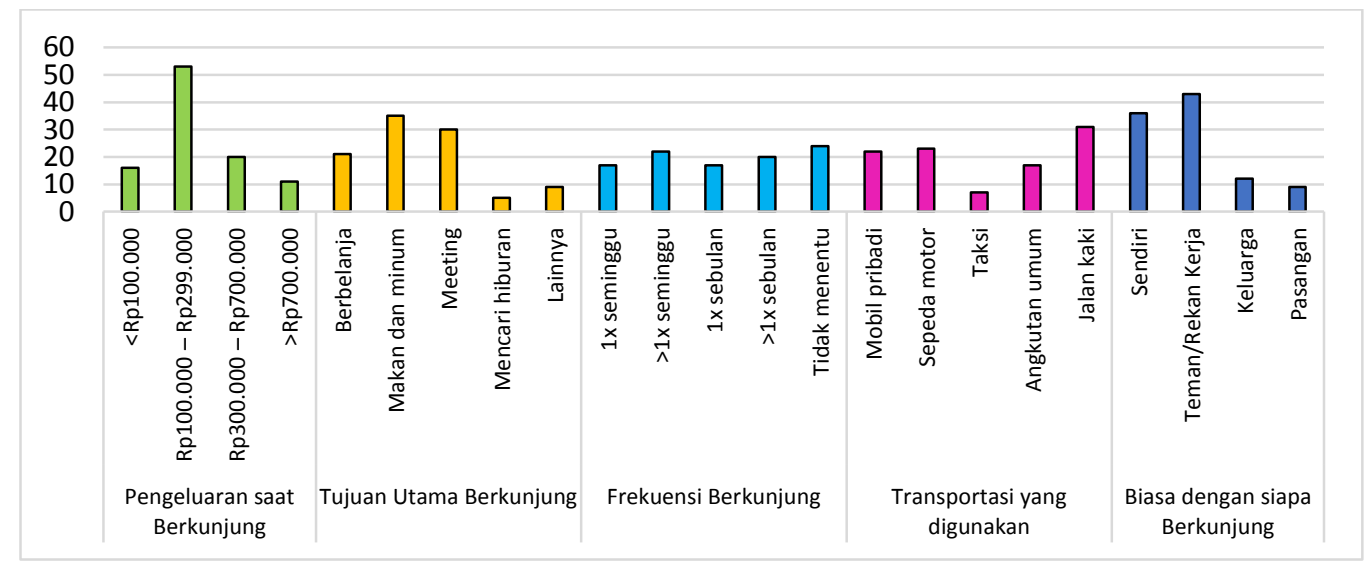

Gambar 10. Tujuan Utama Pengunjung hingga Cost yang dikeluarkan dalam Berkunjung ke Kuningan City Sumber: Hasil olahan angket, 2020

Dapat dilihat dari gambar 10 yang ada, dapat ditarik beberapa hal yaitu Tujuan utama dengan jumlah terbanyak yaitu Makan \& Minum 35\%, diikuti dengan Meeting yaitu 30\%, Frekuensi berkunjung adalah Tidak Menentu sebanyak 24\%, Rekan berkunjung ke Mall Kuningan City adalah Teman/Rekan Kerja yaitu 43\%, Transportasi yang dipakai untuk berkunjung yang paling banyak yaitu pengunjung yang Berjalan Kaki sebesar 31\%, hal ini dapat dipengaruhi karna banyaknya perkantoran, pusat perbelanjaan dan tempat tinggal yang mempunyai jarak sangat dekat dengan objek studi. 
Mall Kuningan City sendiri merupakan bangunan campur (mix-used) yaitu perkantoran sehingga pengunjung utama Mall Kuningan City sendiri adalah pegawai perkantoran yang membantu eksistensi Mall Kuningan City hingga saat ini. Pengeluaran saat berkunjung yang dikeluarkan pengunjung didominasi pada angka pengeluaran sebesar Rp 100.000 hingga Rp 299.000 sebesar $\mathbf{5 3 \%}$, dimana hal ini dipengaruhi oleh tujuan utama pengunjung yang pada umumnya hanya untuk Makan \& Minum atau melakukan Meeting.

\section{Tenancy Mix}

Pengunjung yang datang mempunyai tujuan yang berbeda - beda sehingga jenis penyewa yang dikunjungi juga berbeda - beda, sehingga hasil angket yang disebarkan meliputi jenis penyewa yang menjadi minat pengunjung yang menjadi alasan mereka untuk berkunjung ke Mall Kuningan City, berikut ini tabel yang menjadi hasil dari angket tersebut.

Tabel 7. Jenis Penyewa yang Menjadi Minat Pengunjung Kuningan City

\begin{tabular}{ccc}
\hline No. & Jenis Penyewa & Jumlah \\
\hline $\mathbf{1}$ & Entertainment/Education & 3 \\
\hline $\mathbf{2}$ & Fashion \& Accessories & 14 \\
\hline $\mathbf{3}$ & Food \& Beverages & 38 \\
\hline $\mathbf{4}$ & Hobbies \& Lifestyle & 12 \\
\hline $\mathbf{5}$ & Home Furnishing \& Electronics & 5 \\
\hline $\mathbf{6}$ & Perawatan dan Kosmetik & 12 \\
\hline $\mathbf{7}$ & Supermarket/Lotte Mart & 16 \\
\hline & Responden & 100 \\
\hline
\end{tabular}

Sumber: Hasil angket, 2020

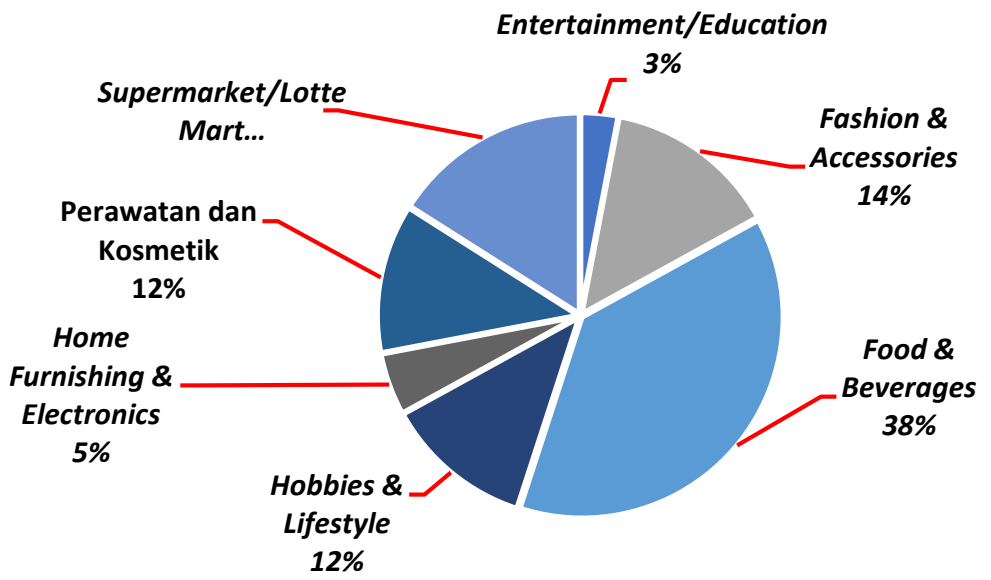

Gambar 11. Preferensi pengunjung mengenai jenis penyewa yang sering dikunjungi/diminati di Kuningan City Sumber: Hasil olahan data angket, 2020

Berikut dari hasil olahan data angket diatas jenis penyewa apa saja yang menjadi tujuan pengunjung untuk datang dan mengunjungi Mall Kuningan City, dimana dari tabel dan grafik diatas menunjukkan bahwa mayoritas pengunjung bertujuan untuk mengunjungi tenant dengan jenis Food \& Beverages sebanyak 38\% kemudian diikuti oleh, Supermarket yang dimiliki Kuningan City yaitu Lotte Mart 16\% dan, Fashion \& Accessories sebesar 14\% dimana banyak sale dan toko berjenis factory outlet dimana barang yang bermerk besar namun sudah out-of-date sehingga harga produk jauh lebih murah dari harga awal produksi barang tersebut. 
Tabel 8. Jenis Penyewa yang Diinginkan atau Ditambah oleh Pengunjung Kuningan City

\begin{tabular}{lll}
\hline No & Jenis Penyewa & Jumlah \\
\hline 1 & Rekreasi keluarga/anak & 10 \\
\hline 2 & Department Store & 27 \\
\hline 3 & Food \& beverages & 19 \\
\hline 4 & Gymnasium & 10 \\
\hline 5 & Fashion \& Acc & 20 \\
\hline 6 & Lainnya & 14 \\
\hline
\end{tabular}

Sumber: Hasil olahan data angket, 2020

Dapat dilihat dari tabel diatas yang merupakan hasil data yang menunjukkan bahwa keinginannya pengunjung dalam menambah jenis penyewa yang ada di Mall Kuningan City, yang dapat kita simpulkan dari hasil data diatas ialah Department store adalah jenis penyewa yang paling diinginkan oleh $27 \%$ pengunjung dimana mengingat Kuningan City belum memiliki jenis penyewa ini dengan jenis General Merchandiser, dibandingkan dengan yang dimiliki oleh kedua kompetitornya yang masing - masing yaitu Lotte Shopping Avenue yaitu Lotte Shopping Avenue dan Lotte Dutty Free dan Kota Kasablanka dengan SOGO, sehingga pengunjung merasa dibutuhkannya penyewa ini.

\section{KESIMPULAN DAN SARAN}

\section{Kesimpulan}

Kondisi pusat perbelanjaan Mall Kuningan dapat disimpukan dari hasil analisa yang dilakukan oleh penulis yaitu Lokasi yang strategis pada jalan arteri dan memiliki banyak aksesibilitas pencapaian menuju lokasi merupakan faktor yang membantu eksistensi Mall Kuningan City hingga sekarang meski jumlah penyewa dan pengunjung yang tidak banyak. Pengunjung Kuningan City yang didominasi oleh Perkantoran yang berada satu gedung dengan Kuningan City dan penduduk yang ada disekitarnya, yang juga masih membantu eksistensi Kuningan City hingga sekarang. Kuningan City mempunyai kompetitor yang sangat kuat yaitu Lotte Shopping Avenue dan Kota Kasablanka yang menjadi salah satu penyebab menurunnya jumlah penyewa dan pengunjung Kuningan City. Masih kurangnya jenis penyewa yang beragam dan juga yang sedang trend untuk menambah minat pengunjung.

\section{Saran}

Setelah proses penilitian dan mendapatkan kesimpulan akhir, terdapat usulan yang dapat disarankan untuk meningkatkan performa/kinerja tingkat hunian penyewa dan arus pengunjung Mall Kuningan City yaitu dimana pengelola harus menambah jenis penyewa terutama jenis General Merchandise seperti Department Store, dan juga mengisi bagian mall yang kosong dengan penyewa yang baru yang up-to-date dan trend pasar yang menjadi permintaan masyarakat saat ini.Bagian Saran hendaknya dibuat dalam paragram yang berbeda, terkait dengan kemungkinan studi atau desain lanjutan.

\section{REFERENSI}

Beyard, M.D. (1999). ULI shopping center handbook series. Urban Land Institute Levy dan Weitz (2004). 5 th edition. Retailing management. New York : McGraw-Hill. Neo, L. W. K., dan Wing, T.K. (2005) The 4Rs of Asian shopping centre management. Singapore: Marshall Cavendish Academic. 